\title{
Vocal cord dysfunction diagnosis may be improved by a screening questionnaire
}

\author{
Marcelo Vivolo Aun ${ }^{1 *}$, Lucia Helena Eduardo Pinto ${ }^{2}$, Jorge Kalil ${ }^{2}$, Rosana Câmara Agondi ${ }^{2}$ Pedro Giavina-Bianchi ${ }^{2}$ \\ From 2nd International Severe Asthma Forum (ISAF) \\ Athens, Greece. 13-15 November 2014
}

\section{Background}

Many patients with vocal cord dysfunction, with or without asthma, receive inappropriate treatment because they are misdiagnosed as having difficult-to-control asthma alone. We developed a clinical screening questionnaire designed to aid the diagnosis of vocal cord dysfunction.

\section{Method}

A prospective observational study involving 80 patients aged $\geq 18$ years, diagnosed with severe asthma. After anamnesis, physical examination, and application of a questionnaire with 6 questions to identify vocal cord dysfunction. $<$ TABLE01> Then patients underwent spirometry and laryngoscopy. On the basis of the laryngoscopic findings, we created three patient groups: vocal cord dysfunction (vocal cord adduction during inspiration, $\mathrm{n}=14$ ); unconfirmed vocal cord dysfunction (inconclusive findings, $n=29$ ); and control (normal findings, $n=37$ ). We attempted to determine whether any of those groups were associated with the responses to individual questions or sets of questions on the questionnaire.

\section{Results}

The proportion of affirmative answers to the question "Does pulmonary auscultation reveal wheezing predominantly in the cervical region, or stridor?" was significantly higher for the vocal cord dysfunction group than for the other two groups $(P=0.006)$. The control group was significantly different from the other two groups in terms of the variable " 4 or more affirmative answers" $(P=0.022)$.

\section{Conclusion}

A finding of wheezing or stridor on auscultation of the cervical region is suggestive of vocal cord dysfunction,

${ }^{1}$ Clinical Immunology and Allergy Division, University of Sao Paulo School of Medicine, Sao Paulo, Brazil

Full list of author information is available at the end of the article especially in elderly patients, and such dysfunction can be confirmed through laryngoscopy. Our screening questionnaire proved effective in discriminating between patients with vocal cord dysfunction and those without.

\section{Authors' details}

'Clinical Immunology and Allergy Division, University of Sao Paulo School of Medicine, Sao Paulo, Brazil. ²University of Sao Paulo School of Medicine, Clinical Immunology and Allergy Division, São Paulo, Brazil.

Published: 23 March 2015

doi:10.1186/2045-7022-5-S2-P12

Cite this article as: Aun et al:: Vocal cord dysfunction diagnosis may be improved by a screening questionnaire. Clinical and Translational Allergy 2015 5(Suppl 2):P12.

\section{Submit your next manuscript to BioMed Central and take full advantage of: \\ - Convenient online submission \\ - Thorough peer review \\ - No space constraints or color figure charges \\ - Immediate publication on acceptance \\ - Inclusion in PubMed, CAS, Scopus and Google Scholar \\ - Research which is freely available for redistribution \\ Submit your manuscript at www.biomedcentral.com/submit}

